\title{
EL CRECIMIENTO DEMOGRÁFICO Y EL DESARROLLO ECONÓMICO LATINOAMERICANO *
}

\author{
VÍCTOR L. URQUIDI \\ El Colegio de México
}

1. EL PROPÓSITO DE ESTE trabajo es explorar algunas relaciones entre el crecimiento demográfico y el desarrollo económico a la luz de factores condicionantes como los que se presentan o pueden presentarse en América Latina. Para ello se hará uso de algunos datos históricos, aunque la atención tendrá que fijarse, más que nada, en los cambios estructurales recientes y en su proyección.

2. La población de América Latina parece haber descendido en términos absolutos durante los siglos XVI y XVII y haber crecido con mucha lentitud hasta fines del siglo XIX.1 Se estima que todavía durante la segunda mitad de este siglo aumentó apenas a razón de $1.3 \%$ al año, tasa muy inferior a la de América del Norte (2.3\%), pero ya muy superior a la del resto del mundo $(0.6 \%)$. Sin embargo, en el decenio 1920-1930, la población latinoamericana se elevó a una tasa anual de $1.8 \%$, frente a $1.4 \%$ en América del Norte y $1.0 \%$ en el resto del mundo. ${ }^{2}$ Desde entonces, la expansión demográfica de América Latina ha sido cada vez más rápida y superior a la de cualquier otra región, y su proyección en los próximos 35 años, conforme a la hipótesis media en los cálculos de las Naciones Unidas, hace suponer que acusará una tasa no inferior a $2.7 \%$ anual, comparada con 1.0-1.2 \% en América del Norte, mientras que en el resto del mundo tenderá al $2.0 \% .^{3}$ Según las últimas estimaciones dadas a conocer por la Comisión Económica para América Latina, en que se tienen en cuenta ajustes recientes a las cifras de varios países con base en trabajos efectuados por el personal técnico del Centro Latinoamericano de Demografía, la tasa de incremento anual a partir de 1960 es ya de $2.8 \%$ anual, y se pro-

* Trabajo presentado al Congreso Mundial de Población, auspiciado por las Naciones Unidas y la Unión Internacional para el Estudio Científico de la Población, Belgrado, Yugoslavia, septiembre de 1965. Documento No 118 (A.9/I/S/118).

1 Kingsley Davis, "La situación de América Latina en la historia demográfica mundial", América Latina (Centro Latinoamericano de Investigaciones en Ciencias Sociales, Río de Janeiro), Año 7, Núm. 2, abril-junio de 1964, pp. 17-19. El autor descansa a su vez en estudios de S. F. Cook, W. Borah; L. B. Simpson, G. Kubler, J. J. Parsons, J. H. Rowe, G. W. Roberts, J. Janer y A. M. Carr-Saunders, citados en su artículo.

2 Ibid., p. 19.

3 Ibid. 
yecta a razón de $2.9 \%$ hasta 1980 , cuando la población total alcanzará 363.6 millones, contra 205.9 en 1960.4

3. La población latinoamericana presenta, en consecuencia, tendencias de aumento sumamente pronunciadas que no tienen precedente en la historia ni paralelo actual en ninguna otra región del mundo. Dichas tendencias son el resultado del descenso rápido de la mortalidad, mientras las tasas de fecundidad, que son elevadas, no han disminuido de manera apreciable. Las proyecciones suponen un descenso apenas moderado de éstas y la continuación de la incidencia declinante de la mortalidad. 5 Ambos factores contribuirán, además, a que la proporción de la población joven (inferior a 15 años) continúe elevándose y a que, por consiguiente, la relación entre la población no activa y la activa aumente. En los últimos treinta años se han reducido considerablemente en América Latina las proporciones de población rural y de población dedicada a actividades agropecuarias, y puede preverse que semejante tendencia continúe manifestándose, dadas las características del desarrollo económico moderno, sobre todo el proceso de industrialización.

4. La perspectiva demográfica de América Latina plantea problemas económicos y sociales sobre cuya magnitud y naturaleza los propios países latinoamericanos carecen de experiencia. La de otros países, en condiciones técnicas, culturales e institucionales diferentes, o que se encuentran en distinta etapa de desarrollo, tal vez tenga utilidad apenas limitada. No obstante, se pueden identificar determinadas consecuencias de una evolución demográfica rápida que son comunes a la mayoría de los países subdesarrollados y que lógicamente se ponen de manifiesto en cuanto se considera la posibilidad de acelerar el desarrollo económico. 6 ,

4 Naciones Unidas, Comisión Económica para América Latina, Botetín Estadístico de América Latina (Santiago de Chile, marzo de 1964), Vol. I, Núm. 1. Cua. dios 1 y 3. Respecto a 1960, el total estimado por la CEPAL coincide con el que da Kingsley Davis (ver nota 1), pero la proyección a 1980 excede en 15 millones $(4.3 \%)$ a la de las Naciones Unidas citada por Davis. La CEPAL hace también ajustes retrospectivos y calcula menos población absoluta entre 1925 y 1960 (diferencia do $5 \%$ en 1930 ).

5 Las poblaciones proyectadas de Argentina, Bolivia, Cuba, Chile y Uruguay -que en 1960 representaban el $20.3 \%$ de la total- acusan tendencias de creciniento menos rápido, sea por descenso de la tasa de natalidad o por disminución menos intensa de la mortalidad en el período considerado. Véase, además de la fuente citada en la nota 4, la comparación por grupos de países hecha por Alfred Sauvy, "La population des pays d'Amérique Latine; vue générale sur leur état et leur croissance", Population (Institut National d'Etudes Demographiques, París), Año 18, Núm. 1, enero-marzo de 1963, pp. 49-64. Véase también el trabajo de Davis antes citado. El estudio de Sauvy se basa en parte en cálculos que han sido modificados posteriormente por la CEPAL. Según las nuevas proyecciones de ésta (loc. cit.), la población de esos cinco países crecerá entre 1960 y 1980 al $1.9 \%$ anual mientras que la de los quince países restantes aumentará a la extraordinaria tasa anual de $3.1 \%$.

6 Véase Ansley J. Coale y Edgar M. Hoover, Population Growth and Economic Development in Low-Income Countries: a case study of India's prospects (Princeton University Press, 1958). (Hay versión al español, Crecimiento de la población $y$ desarrollo económico, editada por Limusa-Wiley, S. A. México, 1965.) En este notable estudio se demuestra que aun en dos economías considerablemente distintas, como son las de la India y México, las consecuencias de una modificación de la tasa de fecundidad son bastante semejantes. Son de interés igualmente las respuestas de diversos gobiernos de países subdesarrollados a un cuestionario de 
5. En primer lugar, se acepta generalmente que el tipo de crecimiento demográfico por el que atraviesa América Latina supone la necesidad de hacer mayor esfuerzo de inversión para dotar a la población ocupada del acervo de capital por persona necesario para los incrementos tradicionales de la producción por habitante. Si, además, se pretendiera elevar ésta con mayor rapidez, el esfuerzo de capitalizaciôn tendría que ser considerablemente mayor, pues se requeriría aumentar el capital por persona ocupada. En segundo lugar, la aceleración del incremento demográfico eleva durante un período largo la proporción de población joven no apta para el trabajo y obliga a la comunidad a destinar mayor proporción de sus recursos a inversiones cuya productividad no es directa o tiene efectos retardados (educación, salud y bienestar, mejoramiento urbano, vivienda) y a proveer servicios corrientes gubernamentales y privados que reducen la capacidad para efectuar nuevas inversiones. En tercer término, se acentúa la gravedad de los problemas estructurales que caracterizan a una economía subdesarrollada, en especial la sobrepoblación rural en áreas de muy baja capacidad técnica, y se intensifican las migraciones de zonas rurales a urbanas, las cuales redundan en subocupación urbana. En cuarto lugar, como consecuencia de lo anterior, surge la necesidad de incrementar la tasa de industrialización a fin de absorber la migración interna, el incremento natural de la población urbana y la reserva de población subocupada. O sea que en un país subdesarrollado el mayor incritmento demográfico resultante de las altas tasas de fecundidad y las decrecientes tasas de mortalidad hace mucho más difícil la realización de un programa de desarrollo cuyos objetivos sean elevar con rapidez el nivel de vida.

6. En el caso de América Latina, la experiencia histórica ha sido muy distinta a la actual. Durante la segunda mitad del siglo xIx la economía de la mayoría de los países latinoamericanos creció bajo el influjo de la demanda de productos básicos ejercida por Europa y Norteamérica. Mientras dicha demanda externa creció con rapidez y se pudo hacer frente a ella sin grandes alteraciones de la estructura interna de los países, casi siempre con ayuda de capital extranjero y aun de población inmigrada, no se hicieron sentir factores que pusieran en evidencia las tendencias demográficas o que modificaran éstas de manera significativa. La población crecía, como ya se dijo, lentamente y la economía se desarrollaba a través de determinados sectores favorecidos por la demanda externa, frecuentemente desvinculados del resto de la economía. Ni las demandas sociales ni el nivel cultural exigían destinar mayor proporción de recursos a las inversiones menos productivas, y el escaso desarrollo industrial y de los servicios significaba que había poco incentivo natural para las migraciones de las zonas rurales a las urbanas. Aunque con fluctuaciones cíclicas de consideración, en las que cada vez se advertían más los desajustes estructurales (por ejemplo, en Brasil, en Argentina, en México), el ingreso por habitante probablemente se elevó a largo plazo, por lo menos en los principales países, aunque a tasa bastante moderada. En Brasil, en Argentina

las Naciones Unidas sobre la acción recíproca del desarrollo económico y los cambios demográficos (Consejo Económico y Social, Doc. E/3895, 18 de mayo de 1964, Cap. III-A). 
y en México puede haber alcanzado un promedio cercano al 1.0-1.5\% al año hasta aproximadamente la primera Guerra Mundial. ${ }^{7}$

7. Este cuadro empezó a variar de manera perceptible después de 1920. Al mismo tiempo que se producía un crecimiento demográfico más rápido, los cambios ocurridos en la estructura de la demanda internacional comenzaron a afectar desfavorablemente a muchos productos básicos latinoamericanos. La crisis del comercio mundial de los años treinta, el descenso de la relación de precios del intercambio después de la segunda Guerra Mundial y los grandes desajustes de oferta y demanda del periodo más reciente han obligado a América Latina, en lo general, a tratar de modificar sustancialmente su estructura productiva y a reorientar la aplicación de sus recursos hacia el mercado interno, en lugar de hacia el exterior. En este proceso ha desempeñado un papel singular la industrialización, a un costo tal vez grande, pero inevitable, y gracias a ello se ha absorbido una parte del incremento demográfico, se han introducido nuevas técnicas y se han creado bases más amplias para la integración económica nacional y regional. Por otro lado, el proceso de urbanización ha contribuido a generalizar los servicios educativos, que es un aspecto positivo de la migración interna.

8. Al mismo tiempo que se ha tenido que hacer el enorme esfuerzo moderno de industrialización, en condiciones adversas y con escasa colaboración del capital extranjero, los países latinoamericanos han tenido que atender en forma proporcionalmente mayor las demandas de servicios sociales, educativos, de vivienda y de mejoramiento urbano que requiere la sociedad contemporánea. En este aspecto la fuerte migración del campo a las ciudades no ha hecho sino intensificar los requisitos de capital, con el resultado de que no se ha hecho frente a las necesidades corrientes, en algunos casos aun se ha perdido terreno relativo y escasamente se satisfacen los niveles cualitativos que sería de desear.

9. Mientras el aumento de la población fue lento, los cambios estructurales implícitos en el desarrollo económico fueron menos urgentes, y podría sostenerse que los mecanismos del mercado, a través de los precios relativos, tanto de productos como de factores, ayudaban a producir desplazamientos suficientes, aunque no del todo eficientes. La agricultura mejoraba y se abrían comunicaciones, y un lento proceso de industrialización, limitado a algunos bienes de consumo, permitía elevar la productividad y encontrar nuevos usos a la técnica y al capital, a la vez que absorbía mano de obra. Pero en cuanto el crecimiento demográfico se volvió rápido, los mecanismos del merçado y los movimientos relativos de los precios dejaron de ser eficaces para inducir las transformaciones estructurales necesarias, $y$ así se explica que grandes sectores rurales y no pocos sectores urbanos industriales se hayan descapitalizado o no hayan podido absorber con la rapidez necesaria capital y técnica que eleven su productividad.

7 Con base en Celso Furtado, Formación económica del Brasil (México, Fondo de Cultura Económica, 1963), pp. 156-157, y 240-241; Aldo Ferrer, La economía argentina (México, Fondo de Cultura Económica, 1963), p. 144; y, respecto a México, datos aún inéditos del Seminario de Historia Moderna de México de El Colegio de México. 
10. La característica actual de América Latina es la subsistencia paralela de sectores de muy alta productividad y sectores de escasa productividad. En la transición de éstos a aquéllos se tropieza con obstáculos institucionales y sociales no fácilmente superables. Por ejemplo, en épocas anteriores podía sostenerse que era menos urgente la reforma agraria debido a que podían elevarse los rendimientos por hectárea en las tierras de cultivo de alta productividad inmediata o potencial, ya fuera en unidades grandes o en las pequeñas; pero en la actualidad, con el incremento demográfico, se ha extendido de tal manera la agricultura de subsistencia, frecuentemente en áreas marginales de escaso potencial productivo, que no son concebibles la transformación de la agricultura y el incremento del nivel de vida rural sin la realización de reformas sustanciales al sistema de tenencia de la tierra, a la organización de la producción agrícola, al sistema de comercialización, a la educación rural, etc. Todos éstos son fenómenos sociales institucionales que no se modifican por el simple funcionamiento de los mecanismos del mercado.

11. Del mismo modo, el desarrollo industrial no responde ya, como antes, a la sola conveniencia de producir artículos en los cuales se posean obvias ventajas de localización, o en que el menor costo de la mano de obra haga posible competir directamente con productos importados similares. La industrialización latinoamericana de la actualidad, impuesta en gran parte por las dificultades de balanza de pagos derivadas de las crisis de los mercados externos y de las consecuencias de los patrones modernos de consumo, supone medidas proteccionistas y estímulos directos, inclusive la construcción de empresas industriales del Estado, todo lo cual relega a segundo plano el funcionamiento de los mecanismos del mercado y el criterio de rentabilidad privada. Hasta hace 20 o 30 años, el incremento demográfico no constituyó un factor que pesara mucho en la política de industrialización; pero el rápido incremento de la población ha dado a la industrialización un nuevo argumento en que apoyarse, que es el de la necesidad de absorber en ocupación más productiva, aun a un costo social elevado, la expansión de la población en edad de trabajar.

12. Si se piensa en el proceso de educación y de mejoramiento cultural, es evidente que en épocas pasadas, aun con escasos esfuerzos por parte del Estado, los servicios educativos se ampliaban y con ellos se elevaba la capacidad técnica media de la población. La falta de interacción entre las zonas ruraleş y las urbanas, y la escasa industrialización, ocultaban, es cierto, las fuertes discrepancias entre la educación urbana y la rural, pero evitaban al menos una presión excesiva sobre los programas educativos. El panorama actual y en perspectiva es radicalmente distinto: la presión para ampliar los servicios educativos, empujada por el rápido descenso de la mortalidad ocurrido en los últimos 15 a 20 años, ha puesto en evidencia lo inadecuados que son dichos servicios, cuantitativa y cualitativamente, y la casi total carencia de los mismos en las zonas rurales. La industrialización exige mano de obra mejor calificada y personal técnico de alta capacidad. El empuje demográfico actual ha acentuado las dificultades en materia educativa y hace prever que se necesitarán reformas tan radicales como lo son en el campo agrícola las reformas al sistema de tenencia de la tierra. 
13. Otro ejemplo lo dan las necesidades de vivienda. Mientras el crecimiento demográfico fue lento y la migración a las ciudades no muy significativa, y en consecuencia la falta de vivienda no se hizo muy patente en su cantidad o en su calidad, el mecanismo normal del sistema de precios respondía aproximadamente a las necesidades. Una gran parte de la vivienda, la rural, estaba en todo caso fuera de ese mecanismo, y la urbana se construía en respuesta a los incentivos ordinarios. Con la mayor tasa de incremento demográfico y el aumento consiguiente de la tasa de formación de familias y del número de personas por familia, todo ello acompañado de números acrecentados de migrantes de bajo poder de compra a las ciudades, el mecanismo de los precios resultó insuficiente para hacer surgir la construcción necesaria de vivienda. No sólo eso, sino que en grandes sectores ha habido deterioro por los fenómenos especiales originados en el cambio de estructura interna de las ciudades $\mathrm{y}$, durante ciertos períodos, en la inflación acompañada de alquileres congelados. En forma creciente, la satisfacción de las necesidades de vivienda en América Latina se ha dejado en manos del sector oficial, o implica por lo menos considerables subsidios al sector privado. Se reconoce que a pesar de los mayores programas de construcción de vivienda en los últimos años, no se ha podido reducir el déficit acumulado en los centros urbanos y apenas se puede hacer frente al incremento de las necesidades normales. Así, la fuerte tasa de expansión demográfica, que en muchas ciudades de América Latina llega al 5 y al $7 \%$ anual, está planteando la necesidad de importantes reformas institucionales y técnicas en ese campo.

14. Generalmente se aducen argumentos en favor de la programación o planeación del desarrollo de América Latina en función de la necesidad de hacer un uso más eficaz de los recursos, estimular la ampliación y la tecnificación de actividades que permitan reducir, a través de la sustitución de importaciones, la dependencia tradicional respecto al comercio exterior, y atender necesidades sociales básicas que la economía de mercado normalmente no satisfaría. Por otro lado, las reformas institucionales y sociales, como la agraria y la educativa, suelen fundamentarse en consideraciones de justicia social y, en parte, en la perspectiva de obtener de ellas resultados económicos a largo plazo. La expansión demográfica, de la que apenas comienza a haber plena conciencia, no ha constituido hasta ahora un factor determinante y justificativo de dichas transformaciones. Es indudable, sin embargo, que a menos de que puedan alterarse apreciablemente las tendencias demográficas, éstas propenderán a pasar a primer plano y a exigir la búsqueda de soluciones con mayor intensidad.

15. Volviendo ahora al punto de partida, o sea a la relación entre el crecimiento demográfico y el esfuerzo de inversión necesario, puede adelantarse que todas las consideraciones anteriores dan mayor relieve a la necesidad de, por un lado, incrementar la capacidad de ahorro interno y de inversión de América Latina y, por otro, procurar la mayor economía posible en el uso del capital y un mayor empleo relativo de mano de obra por unidad de capital. La inversión bruta fija en América Latina no excede todavía de un $15-16 \%$ del producto bruto interno, el coeficiente medio producto/capital es de 0.40-0.45 y la relación margi- 
nal neta producto/capital es también elevada (0.40-0.44). ${ }^{8}$ Esto indica que América Latina, si cuenta con condiciones externas favorables (que son en parte mejorables por negociación internacional), podría hacer el mayor esfuerzo requerido y obtener de él rendimientos en producción bastante considerables.

16. Los especialistas en demografía tienden a expresarse a este respecto en forma relativamente pesimista. En particular, se aferran a una relación población/recursos naturales que no parece corresponder a lo que es la estructura económica moderna. Pero es evidente que el nivel de vida futuro de América Latina no depende de esa relación (si es que algún significado tiene), sino de la capacidad de los países latinoamericanos para integrar su estructura industrial, sea con recursos naturales propios o importándolos, con tal de que existan moderadas posibilidades de incrementar la exportación al resto del mundo, tanto de productos básicos como de manufacturas, y de que el proceso de sustitución de importaciones pueda llevarse adelante en forma más extensa y racional, es decir, que abarque incluso bienes de capital y, a través de la integración regional, pueda aprovechar las economías de la producción en gran escala. Además, considerada América Latina en su conjunto, existen grandes reservas de recursos agrícolas y de productividad potencial que, a través de la integración económica regional, pueden utilizarse en provecho de la propia región; y, en la medida necesaria y en tanto se dé mayor impulso a la industrialización y aun a la exportación de manufacturas, la demanda de alimentos podría complementarse con abastecimientos provenientes de las áreas de clima templado del hemisferio norte donde la productividad y el resto de las condiciones agrícolas, frente a elasticidades-ingreso de la demanda decrecientes, tienden a crear sobrantes permanentes. La estructura de la demanda de consumo ha variado en los países industriales al grado de hacer descender muy apreciablemente la proporción del ingreso destinada a alimentos y, en el caso de muchos productos, de reducir en términos absolutos el consumo por habitante. Este proceso está igualmente presente en áreas de menor desarrollo como América Latina, alentado por el gradual aumento del ingreso y por el cambio cultural implícito en la migración de las zonas rurales a las urbanas. En esta medida se aliviará parte de la presión de la población sobre la agricultura marginal y de subsistencia.

17. Los demógrafos parecen también expresarse con considerable reserva sobre los resultados prácticos del progreso científico y tecnológico en lo que hace a rendimientos agrícolas y aun otros campos de actividad. Pero siempre y cuando se superen obstáculos institucionales y sociales todavía muy evidentes en América Latina, no se ve por qué no haya de esperarse un gran avance técnico que redunde en mayor productividad general del capital, lo cual permitiría a su vez aumentar el capital por persona en edad de trabajar y elevar la productividad por persona ocupada.

18. Se afirma también que un incremento demográfico rápido, como el de América Latina, tiende a reducir la formación del ahorro como pro- 
porción del producto bruto a cualquier nivel de éste, ${ }^{9}$ debido a las consecuencias inevitables que la tasa demográfica elevada tendría en el consumo. Pero esta tendencia, si es que se produce, puede atenuarse por medio de una política de redistribución del gasto en que se limite, en especial por medio de la política tributaria, el aumento del consumo de la población de altos ingresos y se transforme así el consumo excedente en ahorro en manos del sector público, destinable a inversión productiva. Debe admitirse, sin embargo, que de cualquier manera subsiste el problema fundamental de toda economía en desarrollo consistente en elevar su propensión media al ahorro, problema cuya solución no resulta facilitada por la fuerte expansión demográfica.

19. Al considerar el futuro a largo plazo de la economía latinoamericana, y contando con medios internacionales de transporte más baratos, no habría que excluir la posibilidad de migraciones estacionales o de temporada, o aún de mayor permanencia, a las áreas norteamericanas y europeas de elevado nivel de vida, como ya lo presagian los movimientos migratorios de México y Puerto Rico a los Estados Unidos, de Jamaica a Gran Bretaña y Canadá, y la situación en cierto modo paralela de las poblaciones de España, Italia y Grecia al norte y el centro de Europa. En la medida en que continúe emigrando población a Norteamérica y aun a centros europeos de alto nivel de demanda de servicios, tendrá evidentemente cierto alivio el esfuerzo de desarrollo latinoamericano en relación con su dinamismo demográfico propio.

20. Las consideraciones anteriores, con los aspectos optimistas que puedan justificadamente abarcar en cuanto al efecto de la tecnología, la posibilidad de elevar la productividad de capital y de la mano de obra, la influencia de la política fiscal en la propensión media al ahorro y la eventualidad de la migración a largo plazo de determinados sectores de la población latinoamericana, no invalidan, por supuesto, la tesis de que el desarrollo económico de América Latina y la elevación consiguiente del nivel medio de vida serían más rápidos y viables si la tasa de expansión demográfica previsible fuera menor de lo que actualmente se calcula, es decir, en particular si las tasas de fecundidad se redujeran. ${ }^{10}$ Las encuestas que se lleven a cabo en los próximos años sobre fecundidad diferencial y otros aspectos de este problema darán los primeros indicios seguros que permitan revisar, en su caso, las actuales proyecciones demográficas. En igual sentido operará la política de regulación de la natalidad, que cada día parece ser más necesaria. Mientras tanto, para los fines de la programación del desarrollo económico de América Latina, las tasas demográficas que se han citado tendrían que ser tomadas como parámetros. Al tener que reconocerse su relativa permanencia, no es, sin embargo, obligado caer en un "fatalismo demográfico" como el que se aprecia en muchos autores e instituciones, puesto que hay motivo para considerar que la interacción de la tecnología y el cambio social e institucional podría elevar el horizonte de la productividad del capital en forma suficiente para superar la presión demográfica inicial, siempre que se eleven las tasas de inversión y se cuente con cooperación internacional en materia de comercio exterior y de financiamiento a largo plazo.

9 Por ejemplo, Coale y Hoover, op. cit., p. 246, en relación con la India.

10 Cf. Coale y Hoover, $o p$. cit., passim. 